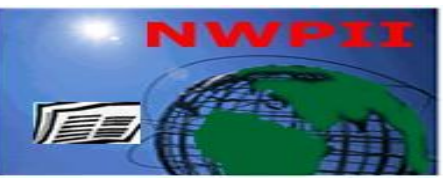

American Journal of Biomedical Sciences

ISSN: 1937-9080

nwpii.com/ajbms

\title{
Tight Interdigitating Developmental Processes within the Thymus; Lessons from Primary Immunodeficiency with Autoimmunity
}

\author{
Sunmi Han ${ }^{1}$ and Young II Choi ${ }^{2}$
}

${ }^{1}$ Clinical and Regulatory Affairs Division, NanoEnTek, Inc, 12F 5 Digital-ro, 26-gil, Guro-gu, Seoul, Republic of Korea

${ }^{2}$ Department of Pharmacology and Toxicology, CKD Research Institute, 315-20 Dongbaekjukjeon-daero, Giheung-gu, Yongin-si, Gyeonggi-do, Republic of Korea

*Corresponding author:

Young Il Choi

Department of Pharmacology and Toxicology

CKD Research Institute,

315-20 Dongbaekjukjeon-daero

Giheung-gu, Yongin-si

Gyeonggi-do 446-916, Republic of Korea

Tel: $+82-31-340-1250$

Fax: +82-31-340-1305;

Email: choiyi@ckdpharm.com or shan@nanoentek.com (Sunmi Han)

Received: 9 October 2014; | Revised: 15 November 2014; | Accepted: 15 December 2014

\begin{abstract}
The underlying cause of the enigmatic coexistence of immunodeficiency and autoimmune disorders in patients with primary immunodeficiency such as Omenn syndrome is largely due to the inefficient negative selection within thymus where $\mathrm{T}$ cells develop. Recent advances in molecular biology and animal models answered one of the key questions on the relationship between the partially impaired $\mathrm{T}$ cell development at early stages and the presence of autoreactive $T$ cells in periphery. $T$ cell development and thymic organogenesis are tightly coupled to each other. The maturing $\mathrm{T}$ cells induce thymic epithelial cell development and AIRE (Autoimmune regulator) expression in thymic medullary epithelial cells. Without thymic medullary epithelial cells and AIRE protein in the patients with primary immunodeficiency, a few autoreactive $\mathrm{T}$ cells survive through the complete thymic selection processes and expand to form oligoclonal $\mathrm{T}$ cell pools in the periphery. The induction of thymic medullary epithelial cell development may be considered as an alternative therapeutic approach in addition to the current standard therapy for primary immunodeficiency - stem cell transplantation.
\end{abstract}

Keywords: Primary Immunodeficiency, Autoimmunity, T cell development, Thymic organogenesis. 


\section{Box 1. Primary Immunodeficiency (PID)}

PID is a heterogeneous group of diseases with more than 180 disease types. The number is still growing with advances in diagnostic technology and increases in early diagnosis. It is characterized by genetic defects in various components of the innate and adaptive immune system, such as neutrophils, macrophages, dendritic cells, complement proteins, natural killer cells, and $\mathrm{T}$ and $\mathrm{B}$ lymphocytes. The study of these diseases has provided essential insights into the functioning of the immune system [1,2]. PID is distinct from Secondary Immunodeficiency Disease originated from infections or treatment of immunomodulatory drugs [3]. The complexity and diversity of the PID has prompted the need for their classification for the diagnosis and treatment (Table 1). DiGeorge syndrome, Wiskott-Aldrich syndrome, Omenn syndrome, Severely Combined ImmunoDeficiency (SCID) belongs to Cellular or Combined Defects type in Table 1. They are well known PIDs in which various genetic defects were found, resulting in abnormalities in DNA repair and/or thymus development $[2,4]$.

Table 1 Type of primary immunodeficiency diseases

\begin{tabular}{|c|c|c|}
\hline $\begin{array}{c}\text { Type of Primary } \\
\text { Immunodeficiency } \\
\text { Diseases }\end{array}$ & Disease & ICD 9* code \\
\hline \multirow{2}{*}{$\begin{array}{c}\text { Antibody Production } \\
\text { Defects }\end{array}$} & X-linked Agammaglobulinemia (Bruton's) & 279.04 \\
\hline & Common Variable Immunodeficiency (CVID) & 279.06 \\
\hline \multirow{2}{*}{\begin{tabular}{c} 
X-linked or Autosomal Hyper IgM Syndrome \\
\hline Defects
\end{tabular}} & Selective IgA Deficiency & 279.05 \\
\hline & Severe Combined Immunodeficiency & 279.01 \\
\hline Phagocytic Cell Immune & DiGeorge Syndrome & 279.2 \\
\hline Defects & Ataxia Telangiectasia & 279.11 \\
\hline & Leukocyte Adhesion Defect & 334.8 \\
\hline & Chronic Granulomatous Disease & 279.12 \\
\hline Complement Defects & Chediak Higashi Syndrome & 288.9 \\
\hline & Cyclic Neutropenia Kostman Diseases & 288.1 \\
\hline & C1 Esterase Inhibitor Deficiency & 288.2 \\
\hline
\end{tabular}

\section{The prevalence of PID}

There appear to be regional differences in the prevalence of PID. For example, incidence in Sweden is 0.35 per 100,000 persons, while in southern Australia a prevalence of 12.4 per
100,000 persons is observed, and it rises to 1 in 1,200 persons in United States. Immunoglobulin deficiency accounts for $70-80 \%$ of all PID $[1,5$, 6]. For the remaining $20-30 \%$, current estimates of PID prevalence are considered reliable for two reasons - the relatively low number of cases and 
the possibility of misdiagnosis due to the similar symptoms of other diseases such as repeated infections.

\section{Risk of PID}

Patients with PID are usually healthy at birth because they are protected by maternal immune system. Nevertheless, they are highly susceptible to various infections after birth. If untreated, PID may result in fatal condition within a couple of years after birth due to repeated infections or even due to inoculation by a recommended live vaccine. The age at diagnosis is significantly associated with survival of patients. In the instance of common variable immunodeficiency (CVID), a major type of PID, a 1-year delay of diagnosis increased the risk of death by $1.7 \%$ every year [7]. The delay of diagnosis was also associated with the likelihood of developing lymphomas or solid tumors, supporting the importance of the early diagnosis and intervention [7].

\section{Diagnosis and treatment of PID}

PID is usually suspected when the patient suffers from repeated infections, unless the diagnosis is made immediately after birth. For example, recurrent sinopulmonary infection, sepsis and CNS infection are associated with antibody or complement deficiency. Recurrent infections on skin or internal organs are associated with phagocytic cell defects. If PID is suspected, serum immunoglobulin and complete

\section{Box2}

DiGeorge syndrome DiGeorge syndrome patients have a hemizygous deletion in chromosome 22q11.2 region ( $90 \%$ of patients) or in chromosome $10 \mathrm{p} 13$ region. This leads to defective development of the third and fourth pharyngeal pouches, resulting in thymic and parathyroid aplasia or hypoplasia together with congenital heart disease and aortic arch abnormality such as truncus arteriosus. Although T cell proliferation is normal after stimulation in most of the DiGeorge syndrome patients, small fragmented thymi may be found in multiple ectopic locations $[12,13]$.

Omenn syndrome Omenn syndrome (OS) is due to several genetic defects for which $\mathrm{T}$ and $\mathrm{B}$ cell development is partially impaired, leading to small numbers of $\mathrm{T}$ and $\mathrm{B}$ cells in peripheral blood. These genetic defects include mutations of Rag1/Rag2, Artemis, IL7R $\alpha$, DNA ligase IV and IL2R $\gamma$. OS patients have a limited TCR repertoire and oligoclonal expansion of autoreactive $\mathrm{T}$ cell clones. These autoreactive $\mathrm{T}$ cells induce autoimmune disorders in various organs. OS patients show thymic aplasia or hypoplasia due to limited T cell development $[14,15]$. 
Within the Primary Immunodeficiency Disease (PID) classification, common variable immunodeficiency (CVID) is the most common type in adults. CVID is characterized by hypogammaglobulinemias with heterogeneous causes. Generally, CVID patients experience recurrent infections in the respiratory and gastrointestinal tracts and autoimmune abnormalities occur in about $30 \%$ of CVID patients [16]. Immunoglobulin replacement therapy and antibiotics treatment are significantly effective for infections but not for the noninfectious autoimmune disorders such as rheumatoid arthritis, lupus and inflammatory bowel disease. This paradoxical manifestation of autoimmune disorders is also observed in various types of PID such as DiGeorge syndrome and Omenn syndrome. The abnormal $\mathrm{T}$ cell development in thymus has been suspected as the main culprit of this peculiar coexistence of autoimmune disorders and immunodeficiency in these PIDs [16].

The association of impaired $\mathrm{T}$ cell development, reduced thymus size and autoimmune disorders in CVID raises an interesting question how $\mathrm{T}$ cell development affects thymic development and subsequent removal of autoreactive $\mathrm{T}$ cells in thymus. With the development of new mouse models, interdependence between $\mathrm{T}$ cells and thymic epithelial cells (TECs) in the thymic development, and its importance in central tolerance has been proposed.

\section{Lack of mTEC and $\mathrm{AIRE}^{+}$cells in PID patients}

Thymus development is a tightly interconnected developmental process of two parallel differentiation processes; $\mathrm{T}$ cell differentiation of bone marrow-derived precursor cells and thymic stromal cell differentiation derived from the third pharyngeal pouch dissociated from the third cleft ectoderm [17]. Precursor $\mathrm{T}$ cells migrate through the complex thymic epithelial network along with chemokine cues for positive and negative selections (Figure 1) $[18]$.

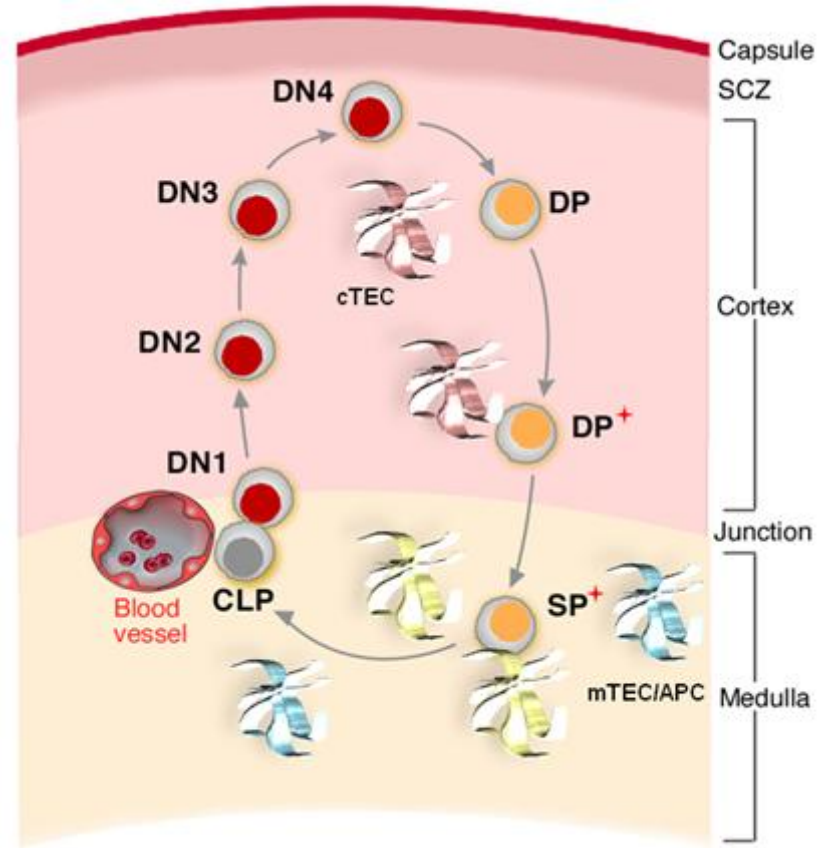

Figure 1. Thymic precursor cells enter the thymus through the blood vessels around corticomedullary junction. They move toward thymic capsule where they rearrange TCR genes. Once they have functional TCR on their surface, they scan peptide-MHC complex on cTEC in the cortex. If they are stimulated by self peptide-MHC complex, they express CD69 and move toward medulla. Aire ${ }^{+}$mTEC express peripheral tissue-specific antigen and present on their surface or provide them to other antigen presenting cells for cross-presentation for the negative selection of putative autoreactive T cells. DN: double negative; DP: $\mathrm{CD}^{+} \mathrm{CD}^{+}$double positive; SP: $\mathrm{CD}^{+}$or $\mathrm{CD}^{+}$ single positive; APC: antigen presenting cells; cTEC: cortical thymic epithelial cells; mTEC: medullary thymic epithelial cells; SCZ: subcapsullary zone. Red cross marks on DP and SP indicates activated $\mathrm{CD} 69^{+}$ thymocytes

At a late developmental period, fetal liverderived hematopoietic stem cells migrate into the thymic anlage and induce thymic organogenesis. Early $\mathrm{T}$ cell development stages are classified based on the expression pattern of cell surface CD molecules such as CD4 and CD8. At initial differentiation stage, thymocytes are double negative (DN) because they express neither CD4 nor CD8. Based on distinct expression patterns for CD25 and CD44, the DN thymocytes are further divided into 4 sequential developmental stages, DN1 $\left(\mathrm{CD} 44^{+} \mathrm{CD} 25^{-}\right), \quad$ DN2 $\left(\mathrm{CD} 44^{+} \mathrm{CD} 25^{+}\right)$, DN3 $\left(\mathrm{C} 44^{-} \mathrm{CD} 25^{+}\right)$and $\mathrm{DN} 4$ 
$\left(\mathrm{CD} 44^{-} \mathrm{CD} 25^{-}\right)$. In the outer cortex of thymus, DN thymocytes express TCR $\beta$ chain and become $\mathrm{CD} 4^{+} \mathrm{CD}^{+}$double positive (DP) thymocytes which fill the most of the thymic cortex. At this DP stage, thymocytes express TCR $\alpha$ chain and scan various self-peptide-MHC complex on thymic epithelial cells and antigen presenting cells. If TCR $\alpha \beta$ complex has appropriate affinity toward particular self-peptide-MHC complex ("positive" selection), the thymocytes express CD69, an early activation marker, and move into the thymic medulla where they further scan peripheral tissue-specific peptide-MHC complex. If TCR $\alpha \beta$ complex does not have a strong affinity toward peptide-MHC complex expressed in the medulla, the thymocytes finish the differentiation and become mature $\mathrm{CD} 4^{+}$or $\mathrm{CD} 8^{+}$ single positive (SP) thymocytes.

The thymic cortical epithelial network develops concomitantly with the early DN stage thymocyte development. This has been clearly demonstrated by the disorganization of the thymic cortex in human $\mathrm{CD} 3 \varepsilon$ transgenic mice where most of thymocytes are arrested at the DN1 stage but thymic cortex is normally differentiated in $\mathrm{Rag} 2^{-/}$mice where thymocytes are arrested at the DN3 stage [19]. These animal data suggests that DN2 or DN3 thymocytes do induce the differentiation of thymic cortical epithelial cells but DN1 thymocytes may not have this capacity.

Thymic medullary epithelial network develops along with the SP thymocyte development. Thus, mice lacking mature $\mathrm{T}$ cells have neither thymic medullary epithelial cells nor AIRE expression [20, 21]. On the other hand, the transplantation of mature SP $\mathrm{T}$ cells induces thymic medullary epithelial cell development in SCID mice lacking thymic medullary structure [22]. After positive selection of DP thymocytes, maturing SP thymocytes migrate into the thymic medulla in response to CCL19 and CCL21 (CCR7 ligands) expressed from thymic medullary epithelial cells for the negative selection of putative autoreactive SP T cells [23]. In $C C R 7^{-/}$ mice or plt/plt mice lacking CCL19/CCL21, maturing SP thymocytes lose the directional migration and induce scattered small thymic medullary structures across the thymus. These results support the hypothesis that thymic medulla development begins with proper $\mathrm{T}$ cell development.

\section{Evidence in PID animal models}

When the $\mathrm{T}$ cell development is partially impaired, a small number of autoreactive $\mathrm{T}$ cells may avoid negative selection by thymic medullary $\mathrm{T}$ cells and proliferate extensively due to the presence of cognate self peptide-MHC complex in the periphery, resulting in autoimmune disorders. The loss of thymic medullary epithelial cells results in loss of AIRE ${ }^{+}$ thymic medullary epithelial cells which present peripheral tissue specific antigen to maturing SP thymocytes for deletion of autoreactive $\mathrm{T}$ cells [21].

In OS model animals such as $\operatorname{Rag} 1^{\text {S723C/S723C }}$, $\operatorname{Rag} 2^{R 229 Q / R 229 Q}$ and ligIV $V^{s / s}$ mutant mice, immune dysregulation was also associated with impaired maturation of thymic epithelial cells due to partial impairment of $\mathrm{T}$ cell development [24. 25]. The leaky maturation of small number of $\mathrm{T}$ cells expanded in these animals resulting in oligoclonality in TCR usage. The OS animal models showed reduced circulating $B$ cells and peripheral eosinophilia in addition to the oligoclonality of T cells. Molecular analysis with several markers clearly proved a severe reduction of cytokeratin $5^{+}$thymic medullary epithelial cells in OS animal models. [25]. This abnormal thymic medulla was associated with reduced thymic expression of Aire and markedly reduced numbers of natural Treg cells and NKT lymphocytes [26].

Treg cells are essential to control immune response to prevent autoimmune disorder and other inflammatory diseases. The impaired development of Treg cells in humans leads to the serious autoimmune disorders such as IPEX syndrome [27, 28]. Treg cells can be divided in two major subsets: natural Treg cells (nTreg; $\left(\mathrm{CD} 4^{+} \mathrm{CD} 25^{+} \mathrm{CD} 127^{\mathrm{dim} / \mathrm{low}} \mathrm{Foxp} 3^{+}\right)$and induced Treg cells (iTreg). Although it is not clear yet the relative contributions of nTreg and iTreg to immunoregulation, recent animal experiment results proved that nTreg and iTreg have distinct roles and act in concert for efficient 
immunomodulation $[29,30]$. In a Foxp3-deficient mouse model, the reconstitution of either nTreg or iTreg partially rescued mice from the disease whereas the transplantation of both nTreg and iTreg prevented more efficiently than that of each subset in isolation [31]. This complementation of nTreg and iTreg functionality may reflect the different ontogeny of these cells leading to development of differing TCR repertoires [31]. nTreg develop in the thymus through high avidity interaction between TCR and self-peptide MHC complex whereas induced Treg cells develop in the periphery [32]. Thus, the reduced nTreg number may be another cause of severe autoimmune disorders in OS animal models.

\section{Evidence in OS patients}

Recently, the analysis result of TCR $\beta$ usage in hypomorphic SCID patients with both immunodeficiency and autoimmune disorders supported that autoimmunity in these patients is associated with the restricted TCR repertoire [33].

OS patients showed unclear corticomedullary demarcation and lacked Hassall' corpuscles, terminally-differentiated epithelial cells, in the thymus. The expression of AIRE and AIREdependent tissue-restricted antigens is severely reduced [34]. In addition, nTreg cells from OS patients showed impaired suppressive activity on comparison with similarly phenotyped cells from healthy donors [35], a result consistent with that observed in the OS animal models.

The pediatric DiGeorge syndrome patients with 22q11.2 deletion showed similar dysregulation of $\mathrm{T}$ cell compartment such as reduced thymic $\mathrm{T}$ cell development, lower $\mathrm{T}$ cell number in periphery, oligoclonal expansion of CD4 $\mathrm{T}$ cell populations and markedly reduced Treg cell numbers [36]

\section{Anti CD3 $\varepsilon$ mAb injection as an therapeutic option for PID patients with thymic hypoplasia}

PID has been treated with stem cell transplantation to rebuild the whole immune system [9]. If it is difficult to find HLA-matched stem cell or bone marrow donor, gene therapy is another option for PID treatment [10]. In the instance of hypomorphic mutation of Rag genes, gene therapy in a preclinical study provided poor reconstitution of immune system due to inadequate Rag gene expression [37]. Instead, the injection of anti-CD $3 \varepsilon$ antibody may be considered as a therapeutic option since antiCD3 $\varepsilon$ antibody can induce thymic organogenesis along with the induction of $\mathrm{T}$ cell development from DN thymocytes by crosslinking TCR complex on immature thymocytes [38].

\section{Box 3. Aire}

Aire is a transcription factor which induces ectopic promiscuous expression of a large number of genes normally expressed in peripheral tissues. Aire ${ }^{+}$mTEC induces negative selection of $\mathrm{T}$ cells that are specific to peripheral tissue specific antigens as well as the differentiation of nTreg cells that represses $\mathrm{T}$ cell activation in periphery. The deletion of Aire results in defective negative selection of autoreactive thymocytes, which escape into the peripheral tissue and induces significant autoimmune responses. Aire is a proapoptotic gene which is expressed at the final maturation stage of mTEC. The death of Aire ${ }^{+}$mTEC may promote cross-presentation of the peripheral tissue-specific antigens encoded by Aire-induced transcripts in mTEC $[40,41]$.

In $\mathrm{TCR} \beta^{+/+} \operatorname{Rag}^{-/-}$mice, $\mathrm{T}$ cell development is blocked at DP stage due to the lack of TCR $\alpha$ chain and thymus has cortex without medulla due to the lack of maturing SP T cells. The injection of anti-CD3 mAb activated DP thymocytes and induced ER-TR5 ${ }^{+} \mathrm{UEA}^{+}$ cytokeratin $^{+}$cytokeratin8 $^{-}$thymic medullary structures [39]. In a $\operatorname{Rag} 2^{\mathrm{R} 229 \mathrm{Q} / \mathrm{R} 229 \mathrm{Q}}$ OS mouse model, the injection of anti-CD3e antibody activated DP thymocytes and induced UEA1 ${ }^{+}$ cytokeratin $^{+}$cytokeratin $^{-}$thymic medullary structure [25]. Thus, the injection of anti-CD3e antibody may be applicable to other PID diseases associated with impaired thymic development to control autoimmune manifestations via facilitating negative selection of autoreactive 
thymocytes and development of natural Treg cells [38].

\section{Acknowledgement}

We acknowledge the careful comment on the manuscript from Jonathan Duke-Cohan Ph.D, Dana-Farber Cancer Institute, Harvard medical school.

\section{References}

1. Ruest, C. Evaluation of Primary Immunodeficiency Disease in Children. Am Fam Physician, 2013, 87(11),773-778. DOI: $\underline{10.3928 / 00904481-20110316-08}$

2. McCusker, C.; Warrington R. Primary Immunodeficiency. Allergy, Asthma \& Clinical Immunology, 2011, 7(Suppl 1):S11. DOI: 10.1186/1710-1492-7-S1-S11

3. Woodbinea, L.; Genneryb, A.; Jeggo, P. Reprint of "The clinical impact of deficiency in DNA non-homologousend-joining". DNA Repair, 2014, 17:9-20. DOI: 10.1016/j.dnarep.2014.04.002

4. Chinen, J.; Shearer, W. Secondary immunodeficiencies, including HIV infection. J Allergy Clin Immunol, 2010, 125(2 Suppl 2):S195-203.DOI: 10.1016/j.jaci.2009.08.040

5. Boyle, J.; Buckley, R. Population Prevalence of Diagnosed Primary Immunodeficiency Diseases in the United States. J Clin Immunol, 2007, 27(5), 497-502. DOI: 10.1007/s10875007-9103-1

6. Baumgart, K.; Britton, W.; Kemp, A.; French, M.; Roberton, D. The spectrum of primary immunodeficiency disorders in Australia. $J$ Allergy Clin Immunol, 1997, 100(3), 415-423. DOI: 10.1016/S0091-6749(97)70257-4

7. Gathmann, B. et al. Clinical picture and treatment of 2212 patients with common variable immunodeficiency. J Allergy Clin Immunol, 2014, 134(1), 116-126. DOI: 10.1016/j.jaci.2013.12.1077

8. Puck, J. Laboratory technology for population-based screening for severe combined immunodeficiency in neonates: The winner is T-cell receptor excision circles.
J Allergy Clin Immunol, 2012, 129(3), 607616. DOI: 10.1016/j.jaci.2012.01.032

9. Pai, S. et al. Transplantation Outcomes for Severe Combined Immunodeficiency, 2000 2009. N Engl J Med, 2014, 371(5), 434-446. DOI: 10.1056/NEJMoa1401177

10. Qasim, W.; Gennery, A. Gene Therapy for Primary Immunodeficiencies: Current Status and Future Prospects. Drugs, 2014, 74(9), 963-969. DOI: 10.1007/s40265-014-0223-7

11. Kwan, A. et al. Newborn screening for severe combined immunodeficiency in 11 screening programs in the United States. JAMA, 2014, 312(7), 729-738. DOI: 10.1001/jama.2014.9132

12. Daw, S.; Taylor, C.; Kraman, M.; Call, K.; Mao, J.; Schuffenhauer, S.; Meitinger, T.; Lipson, T.; Goodship, J.; Scambler, P. A common region of $10 \mathrm{p}$ deleted in DiGeorge and velocardiofacial syndromes. Nature Genetics, 1996, 13(4), 458 - 460. DOI: 10.1038/ng0896-458

13. Bassett, A.; McDonald-McGinn, D.; Devriendt, K.; Digilio, M.; Goldenberg, P.; Habel, A.; Marino, B.; Oskarsdottir, S.; Philip, N.; Sullivan, K.; Swillen, A.; Vorstman, J.; International 22q11.2 Deletion Syndrome Consortium. Practical Guidelines for Managing Patients with 22q11.2 Deletion Syndrome. J Pediatr, 2011, 159(2), 332339.e1. DOI: 10.1016/j.jpeds.2011.02.039

14. Villa, A.; Notarangelo, L.; Roifman, C. Omenn syndrome: Inflammation in leaky severe combined immunodeficiency. $J$ Allergy Clin Immunol, 2008, 122(6), 10821086. DOI: 10.1016/j.jaci.2008.09.037

15. Notarangelo, L.; Ganmbineri, E.; Badolato, R. Immunodeficiencies with autoimmune consequences. Adv Immunol. 2006, 89, 321370. DOI: $10.1016 /$ S0065-2776(05)89008-X

16. Salzer, U.; Warnatz, K.; Peter, H. Common variable immunodefi ciency - an update. Arthritis Research \& Therapy, 2012, 14(5), 223. DOI: $10.1186 / \mathrm{ar} 4032$

17. Rodewald, H. Thymus organogenesis. Annu. Rev. Immunol. 2008, 26, 355-388. DOI: 10.1146/annurev.immunol.26.021607.090408

18. Anderson, G.; Jenkinson, E. Lymphostromal interactions in thymic development and 
function. Nat. Rev. Immunol., 2001, 1(1), 3140. DOI: $10.1038 / 35095500$

19. Klug, D.; Carter, C.; Crouch, E.; Roop, D.; Conti, C.; Richie, E. Interdependence of cortical thymic epithelial cell differentiation and T-lineage commitment. Proc. Natl. Acad. Sci. USA, 1998, 95(20), 11822-11827. DOI: 10.1073/pnas.95.20.11822

20. Shores, E.; Van Ewijk, W.; Singer, A. Maturation of medullary thymic epithelium requires thymocytes expressing fully assembled CD3-TCR complexes. Int. Immunol., 1994, 6(9), 1393-1402. DOI: 10.1093/intimm/6.9.1393

21. Cavadini, P.; Vermi, W.; Facchetti, F.; Fontana, S.; Nagafuchi, S.; Mazzolari, E.; Sediva, A.; Marrella, V.; Villa, A.; Fischer, A.; Notarangelo, L.; Badolato, R. AIRE deficiency in thymus of 2 patients with Omenn syndrome. J. Clin. Invest., 2005, 115(3), 728-732. DOI: 10.1172/JCI200523087

22. Surh, C.; Ernst, B.; Sprent, J. Growth of epithelial cells in the thymic medulla is under the control of mature T cells. J. Exp. Med., 1992, 176(2), 611-616. DOI: 10.1084/jem.176.2.611

23. Uehara, S.; Song, K.; Farber, J; Love, P. Characterization of CCR9 expression and CCL25/thymus-expressed chemokine responsiveness during $\mathrm{T}$ cell development: $\mathrm{CD} 3^{\text {high }} \mathrm{CD} 9^{+}$thymocytes and gammadeltaTCR ${ }^{+}$thymocytes preferentially respond to CCL25. J. Immunol., 2002, 168(1), 134-142. DOI: $\underline{10.4049 / j i m m u n o l .168 .1 .134}$

24. Rucci, F.; Poliani, P.; Caraffi, S.; Paganini, T.; Fontana, E.; Giliani, S.; Alt, F.; Notarangelo, L. Abnormalities of thymic stroma may contribute to immune dysregulation in murine models of leaky severe combined immunodeficiency. Front. Immun., 2011, 2, $15 . \quad$ DOI: $\underline{10.3389 / \text { fimmu.2011.00015 }}$

25. Marrella, V.; Poliani, P.; Notarangelo, L.; Villa, A. Rag defects and thymic stroma: lessons from animal models. Front Immunol., 2014, $5, \quad 259 . \quad$ DOI: $\underline{10.3389 / \text { fimmu.2014.00259 }}$
26. Marrella, V.; Poliani, P.; Casati, A.; Rucci, F.; Frascoli, L.; Gougeon, M.; Lemercier, B.; Bosticardo, M.; Ravanini, M.; Battaglia, M.; Roncarolo, M.; Cavazzana-Calvo, M.; Facchetti, F.; Notarangelo, L.; Vezzoni, P.; Grassi, F.; Villa, A. A hypomorphic R229Q Rag2 mouse mutant recapitulates human Omenn syndrome. J. Clin. Invest., 2007, 117(5), 1260-1269. DOI: 10.1172/JCI30928

27. Bennett, C.; Christie, J.; Ramsdell, F.; Brunkow, M.; Ferguson, P.; Whitesell, L.; Kelly, T.; Saulsbury, F.; Chance, P.; Ochs, H. The immune dysregulation, polyendocrinopathy, enteropathy, X-linked syndrome (IPEX) is caused by mutations of FOXP3. Nat Genet, 2001, 27(1), 20-21. DOI: $\underline{10.1038 / 83713}$

28. Wildin, R.; Ramsdell, F.; Peake, J.; Faravelli, F.; Casanova, J.; Buist, N.; Levy-Lahad, E.; Mazzella, M.; Goulet, O.; Perroni, L.; Bricarelli, F.; Byrne, G.; McEuen, M.; Proll, S.; Appleby, M.; Brunkow, M. X-linked neonatal diabetes mellitus, enteropathy and endocrinopathy syndrome is the human equivalent of mouse scurfy. Nat Genet, 2001, 27(1), 18-20. DOI: 10.1038/83707

29. Mucida, D.; Kutchukhidze, N.; Erazo, A.; Russo,M.; Lafaille, J.; Curotto de Lafaille, M. Oral tolerance in the absence of naturally occurring Tregs. J. Clin. Invest., 2005, 115(7), 1923-1933. DOI: 10.1172/JCI24487

30. Curotto de Lafaille, M.; Kutchukhidze, N.; Shen, S.; Ding, Y.; Yee, H.; Lafaille, J. Adaptive Foxp3+ regulatory T cell-dependent and -independent control of allergic inflammation. Immunity, 2008, 29(1), 114126. DOI: 10.1016/j.immuni.2008.05.010

31. Haribhai, D.; Williams, J.; Jia, S.; Nickerson, D.; Schmitt, E.; Edwards, B.; Ziegelbauer, J.; Yassai, M.; Li, S.; Relland, L.; Wise, P.; Chen, A.; Zheng, Y.; Simpson, P.; Gorski, J.; Salzman, N.; Hessner, M.; Chatila, T.; Williams, C. A requisite role for induced regulatory $\mathrm{T}$ cells in tolerance based on expanding antigen receptor diversity. Immunity, 2011, 35(1):109-122. DOI: 10.1016/j.immuni.2011.03.029

32. Curotto de Lafaille, M.; Lafaille, J. Natural and adaptive foxp $3+$ regulatory $\mathrm{T}$ cells: more 
of the same or a division of labor? Immunity, 2009, 30(5), 626-635. DOI: 10.1016/j.immuni.2009.05.002

33. de Villartay, J.; Lim, A.; Al-Mousa, H.; Dupont, S.; Déchanet-Merville, J.; CoumauGatbois, E.; Gougeon, M.; Lemainque, A.; Eidenschenk, C.; Jouanguy, E.; Abel, L.; Casanova, J.; Fischer, A.; Le Deist, F. A novel immunodeficiency associated with hypomorphic RAG1 mutations and CMV infection. J Clin Invest, 2005, 115(11), 32913299. DOI: 10.1172/JCI25178

34. Cavadini, P.; Vermi, W.; Facchetti, F.; Fontana, S.; Nagafuchi, S.; Mazzolari, E.; Sediva, A.; Marrella, V.; Villa, A.; Fischer, A.; Notarangelo, L.; Badolato, R. AIRE deficiency in thymus of 2 patients with Omenn syndrome. J Clin Invest. 2005, 115(3), 728-732. DOI: 10.1172/JCI200523087

35. Cassani, B.; Poliani, P.; Marrella, V.; Schena, F.; Sauer, A.; Ravanini, M.; Strina, D.; Busse, C.; Regenass, S.; Wardemann, H.; Martini, A.; Facchetti, F.; van der Burg, M.; Rolink, A.; Vezzoni, P.; Grassi, F.; Traggiai, E.; Villa, A. Homeostatic expansion of autoreactive immunoglobulin-secreting cells in the Rag2 mouse model of Omenn syndrome. J Exp Med., 2010, 207(7), 15251540. DOI: $10.1084 /$ jem.20091928

36. Ferrando-Martínez, S,; Lorente, R.; Gurbindo, D.; De José, M.; Leal, M.; Muñoz-Fernández, M.; Correa-Rocha, R. Low Thymic Output, Peripheral Homeostasis Deregulation, and Hastened Regulatory T Cells Differentiation in Children with 22q11.2 Deletion Syndrome. $J$ Pediatr., 2014, 164(4), 882-889. DOI: 10.1016/j.jpeds.2013.12.013

37. van Til, N.; Sarwari, R.; Visser, T.; Hauer, J.; Lagresle-Peyrou, C.; van der Velden, G.; Malshetty, V.; Cortes, P.; Jollet, A.; Danos,
O.; Cassani, B.; Zhang, F.; Thrasher, A.; Fontana, E.; Poliani, P.; Cavazzana, M.; Verstegen, M.; Villa, A.; Wagemaker, G. Recombination-activating gene 1 (Rag1)deficient mice with severe combined immunodeficiency treated with lentiviral gene therapy demonstrate autoimmune Omenn-like syndrome. J Allergy Clin Immunol., 2014, 133(4), 1116-1123. DOI: 10.1016/j.jaci.2013.10.009

38. Marrella, V.; Poliani, P.; Fontana, E.; Casati, A.; Maina, V.; Cassani, B.; Ficara, F.; Cominelli, M.; Schena, F.; Paulis, M.; Traggiai, E.; Vezzoni, P.; Grassi, F.; Villa, A. Anti-CD3e mAb improves thymic architecture and prevents autoimmune manifestations in a mouse model of Omenn syndrome: therapeutic implications. Blood. 2012, 120, 1005-1014. DOI: 10.1182/blood2012-01-406827

39. Choi, Y.; Duke-Cohan, J.; Tan, J.; Gui, J.; Singh, M.; Epstein, J.; Reinherz, E. Plxnd1 Expression in Thymocytes Regulates Their Intrathymic Migration While That in Thymic Endothelium Impacts Medullary Topology. Front Immunol., 2013, 4, 392. DOI: 10.3389/fimmu.2013.00392

40. Mathis, D.; Benoist, C. Aire. Ann Rev of Immunol., 2009, 27, 287-312. DOI: 10.1146/annurev.immunol.25.022106.141532

41. Perry, J.; Lio, C.; Kau, A.; Nutsch, K.; Yang, Z.; Gordon, J.; Murphy, K.; Hsieh, C. Distinct Contributions of Aire and AntigenPresenting-Cell Subsets to the Generation of Self-Tolerance in the Thymus. Immunity, 2014, 41, 414-426. DOI: 10.1016/j.immuni.2014.08.007 